\title{
Viral myocarditis simulating dilated cardiomyopathy in early childhood: evaluation by serial echocardiography
}

\author{
ELLIOTT WEINHOUSE, * KENNETH L WANDERMAN, * SHAUL SOFER, $†$ \\ YEHOSHUAH GUSSARSKY, MOSCHE GUERON*
}

From the ${ }^{\star}$ Department of Cardiology and $†$ Paediatric Intensive Care Unit, Soroka Medical Centre and Corob Centre for Health Sciences, Ben-Gurion University of the Negev, Beer-Sheva, Israel

SUMMARY Left ventricular dimensions and function were assessed by serial M mode and cross sectional echocardiography in ten infants and young children with heart muscle disease characterised by left ventricular dilatation and impaired systolic function presenting in congestive heart failure, severe respiratory distress, or both. The patients were followed for 8-60 months after their initial admission. The aetiology was probably viral in all cases. One patient died three weeks after diagnosis. Left ventricular size and function returned to normal in only one child; however, various degrees of improvement were found in seven others who were symptom free at follow up.

This study demonstrates that serial echocardiography adequately defines this disease in infants and young children and that invasive evaluation is seldom required. Furthermore, it emphasises the fact that even in symptom free children an echocardiographic picture that is indistinguishable from dilated cardiomyopathy may persist; such patients require continued follow up.

Echocardiography has been used extensively in the evaluation of adults with heart muscle diseases that result in a dilated left ventricle with impaired systolic function. Few reports, however, have described this technique in the management and follow up of children. ${ }^{1-3}$ We present our experience in ten infants and young children who were followed for eight to 60 months by serial M mode and cross sectional echocardiographic studies after their initial admission to our hospital with congestive heart failure.

\section{Patients and methods}

From 1980-1985 ten infants and young children (aged 2.5 to 24 months) were admitted to Soroka Medical Centre in congestive heart failure with a

Requests for reprints to Dr Kenneth $L$ Wandermañ, Department of Cardiology, Soroka Medical Centre, PO Box 151, Beer-Sheva 84101, Israel.

Accepted for publication 17 February 1986 dilated and poorly functioning left ventricle. Neurological, metabolic, and drug induced disease and valvar or congenital heart lesions had been excluded in all of them. There were five males and five females. Four children required admission to the paediatric intensive care unit because of severe respiratory failure or multisystem viral illness or both. One child developed renal failure and three had hepatocellular dysfunction in addition to congestive heart failure. Cytomegalovirus was isolated in one child, echovirus in another, and Coxsackie B in two others. Coxsackie antibody titres were suggestive of recent infection in an additional child. All ten had histories that were compatible with previous viral illness.

In all patients a thorough history was obtained and a physical examination was performed. Routine studies included blood gases, electrocardiograms, and chest $x$ rays. After congestive heart failure became apparent, all children underwent complete echocardiographic studies including Mmode and cross sectional examinations in all accepted planes by means of an Aloka Echocardiograph SSD-110S 
Results of serial echocardiography in 10 children with dilated cardiomyopathy

\begin{tabular}{|c|c|c|c|c|c|c|c|c|c|}
\hline Sex & $\begin{array}{l}\text { Age } \\
\text { (mnths) }\end{array}$ & $\begin{array}{l}\text { MV } \\
\text { Eto IVS } \\
\text { ( } \mathrm{mm})\end{array}$ & $\underset{(\mathrm{mm})}{L A(E S D)}$ & $\begin{array}{l}\text { IVS } \\
\text { thickness } \\
(\mathrm{mm})\end{array}$ & $\begin{array}{l}\text { LV PW } \\
\text { thickness } \\
\text { (mm) }\end{array}$ & $\underset{(m m)}{L V D d}$ & $\begin{array}{l}L V \\
\triangle D^{\prime \prime} \\
(29-42)\end{array}$ & $\begin{array}{l}\text { Clinical } \\
\text { data }\end{array}$ & Treatment \\
\hline $\mathbf{F}$ & 12 & 25 & $14(16-19)$ & $4(4-6)$ & $8(4-5)$ & $44(26-29)$ & $<10$ & $\begin{array}{l}\text { CHF, died } \\
3 \text { wks later }\end{array}$ & $\begin{array}{l}\text { D, F, } \\
\text { dop, hyd }\end{array}$ \\
\hline M & 7 & 23 & $22(17-18)$ & $4(4-5)$ & $5(4-5)$ & $48(26-28)$ & 15 & $\mathrm{CHF}$ & $\mathrm{D}$ \\
\hline & 15 & 17 & $22(18-21)$ & $5(4-6)$ & $5(4-6)$ & $35(27-31)$ & 17 & Symptom free & D \\
\hline \multirow[t]{3}{*}{$M$} & 10 & 12 & $28(18-20)$ & $3(4-5)$ & $5(4-5)$ & $37(27-30)$ & 24 & $\mathrm{CHF}$ & D, hyd \\
\hline & 11 & 12 & $18(18-20)$ & $4(4-5)$ & $5(4-5)$ & $37(27-30)$ & 22 & $\mathrm{CHF}$ & D, hyd \\
\hline & 22 & 8 & $19(19-21)$ & $5(4-6)$ & $5(4-6)$ & $38(29-31)$ & 34 & Symptom free & $D$, hyd \\
\hline \multirow[t]{2}{*}{$\mathbf{F}$} & 6 & 18 & $15(12-14)$ & $4(4-5)$ & $4(4-5)$ & $45(26-29)$ & 13 & $\mathrm{CHF}$ & D \\
\hline & 20 & 12 & $18(18-21)$ & $6(4-6)$ & $6(4-6)$ & $40(27-31)$ & 18 & Symptom free & D \\
\hline \multirow[t]{3}{*}{$\mathbf{M}$} & 18 & 27 & $32(19-20)$ & $4(4-6)$ & $5(4-6)$ & $55(29-31)$ & 15 & $\mathrm{CHF}$ & D \\
\hline & 24 & 13 & $25(19-21)$ & $5(4-6)$ & $5(4-6)$ & $42(29-31)$ & 21 & Symptom free & I) \\
\hline & 32 & 11 & $22(20-22)$ & $5(5-6)$ & $5(5-6)$ & $36(31-32)$ & 28 & Symptom free & D \\
\hline \multirow[t]{3}{*}{$\mathbf{F}$} & 24 & 25 & $29(18-19)$ & $4(4-6)$ & $4(4-6)$ & $47(27-29)$ & 11 & $\mathrm{CHF}$ & $D, F$ \\
\hline & 25 & 25 & $32(18-19)$ & $4(4-6)$ & $3(4-6)$ & $49(27-29)$ & 18 & $\mathrm{CHF}$ & $\mathrm{D}, \mathrm{F}$ \\
\hline & 42 & 18 & $30(19-20)$ & $4(5-6)$ & $4(5-6)$ & $51(29-31)$ & 18 & C.HF & $\mathrm{D}, \mathrm{F}$ \\
\hline \multirow[t]{2}{*}{ M } & 10 & 10 & $22(18-19)$ & $6(4-5)$ & $6(4-5)$ & $37(27-29)$ & 19 & $\mathrm{CHF}$ & I) \\
\hline & 36 & $<5$ & $18(20-22)$ & $6(5-7)$ & $7(5-7)$ & $28(31-32)$ & 32 & Recovered & None \\
\hline \multirow[t]{3}{*}{$\mathbf{F}$} & 21 & 25 & $30(19-20)$ & - & - & $45(29-31)$ & - & $\mathrm{CHF}$ & $\mathrm{D}, \mathrm{F}$ \\
\hline & 27 & 21 & $34(19-20)$ & $4(4-6)$ & $6(4-6)$ & $57(29-31)$ & 18 & $\mathrm{CHF}$ & $\mathrm{D}, \mathrm{F}$ \\
\hline & 48 & 13 & $24(21-23)$ & $5(5-6)$ & $7(5-6)$ & $43(32-34)$ & 30 & Symptom free & D \\
\hline \multirow[t]{2}{*}{$\mathbf{F}$} & 15 & 23 & $36(19-20)$ & $4(4-5)$ & $5(4-5)$ & $55(28-30)$ & 13 & $\mathrm{CHF}$ & D \\
\hline & 48 & 27 & $19(21-23)$ & $4(5-6)$ & $7(5-6)$ & $47(32-34)$ & 19 & Symptom free & I) \\
\hline \multirow[t]{4}{*}{$\mathbf{M}$} & 2.5 & 13 & $22(10-16)$ & $4(3-4)$ & $4(3-4)$ & $32(15-22)$ & 12 & $\mathrm{CHF}$ & $\mathrm{I}, \mathrm{F}$ \\
\hline & 5 & 20 & $26(17-18)$ & $4(4-5)$ & $4(4-5)$ & $39(26-28)$ & 10 & $\mathrm{CHF}$ & $\mathrm{D}, \mathrm{F}$ \\
\hline & 14.5 & 5 & $26(18-19)$ & $5(4-5)$ & $5(4-5)$ & $32(27-29)$ & 22 & Symptom free & D \\
\hline & 62 & 6 & $28(23-24)$ & $4(5-6)$ & $5(5-6)$ & $39(34-35)$ & 28 & Symptom free & None \\
\hline
\end{tabular}

malve; E, E point; IVS, interventricular septum; LA, left atrium; ESD, end systolic diameter; PW, posterior wall; LV, left ventricle; Dd, end diameter; $A D^{\circ}{ }_{1 .}$, shortening percentage; $D$, digoxin; $F$, frusemide; dop, dopamine; hyd, hydralazine; CHF, congestive heart failure. in in parentheses are normal values.

and a Sony Betamax video recorder. The Table outlines the serial studies that were performed. Ten consecutive beats were averaged to assess chamber dimensions. The normal values that we used were those of Goldberg et al. ${ }^{4}$ Cross sectional measurements were used to confirm the accuracy and positioning of the $\mathrm{M}$ mode dimensions.

\section{Results}

The initial measurements (Table and Figs. 1-3) of left ventricular end diastolic dimensions, systolic dimensions, and systolic shortening indicate left ventricular dilatation and moderately to severely impaired systolic function in each patient. In eight children the left ventricular cavity was smaller on follow up, but in only one did the dimensions return to normal, though all of these children became symptom free. Initial left ventricular systolic shortening ranged from $<10^{\prime \prime}$ " to $24^{\prime \prime}$ ", though most patients had values between $12^{\prime \prime}$ " and $15^{\circ}$ " (normal $29-42^{\circ}{ }_{0}$ ). The child in whom left ventricular systolic shortening was $<10^{\prime \prime}$ " (case 1) died shortly after presentation. In six cases the left atrium was enlarged and in two others there was borderline enlargement. In seven of these, left atrial size had returned to normal on follow up. In our most severely affected case (who died) the size of the left atrium was normal.

The distance from the anterior mitral leaflet $\mathrm{E}$ point to the interventricular septum initially ranged from 10 to $27 \mathrm{~mm}$; the normal mean (ISD) value for children is reported to be $2(1 \cdot 2) \mathrm{mm} .{ }^{3}$ We measured this dimension in 15 very young children with normal left ventricular function and our result (3 $(1.5) \mathrm{mm})$ is consistent with previously reported normal values. ${ }^{3}$ Thus an increase in this variable indicates poor left ventricular function.

Only one patient had thickening of the left ventricular free wall (Fig. 1). This patient deteriorated rapidly and died three weeks after admission (case 1). None of our patients had thickening of the interventricular septum. In all cases reduced left ventricular function was symmetrical, and hypokinesia did not preferentially affect the posterior wall as has been reported by others ${ }^{2}$ In case 1 we used the technique described by Van der Hauwaert et al $^{3}$ and showed dense echoes along the entire interior aspect of the left ventricular cavity, predominantly affecting the posterior wall. Unlike Kupferschmid et $a^{5}$ we found no evidence of left ventricular thrombi in any of the 25 echocardiographic studies that we performed.

One child (case 1) died (three weeks after initial admission), one (case 7) may be considered to have recovered (26 months later), one (case 6 ) continues to have symptoms and echocardiographic features are unchanged 18 months later, and seven children (cases 2-5, 8-10) who have no symptoms show varying degrees of improved left ventricular function 


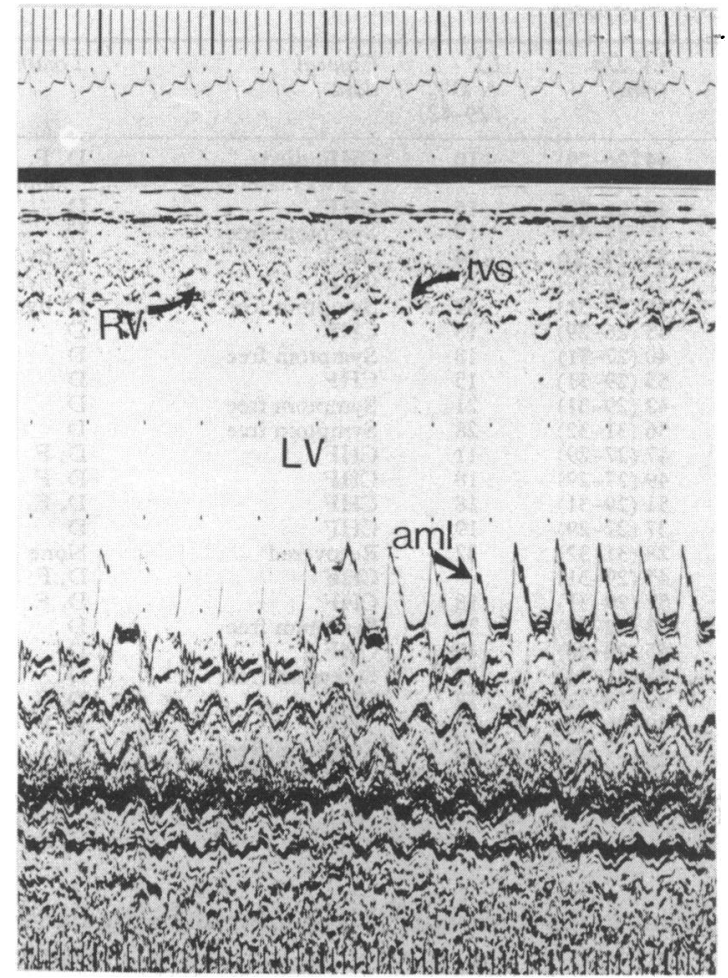

Fig. $1 M$ mode echocardiogram from case 1 . showing dilated left ventricular $(L V)$ cavity and increased anterior mitral leaflet (aml) to interventricular septum (IVS) separation that is typically seen in dilated cardiomyopathy. The posterior wall is thickened. $R V$, right ventricle. and decreased left ventricular dimensions eight to 60 months later. All children took digoxin with or without diuretics, peripheral vasodilators, or both. Our study group is not sufficiently large to evaluate the effects of these therapeutic regimens.

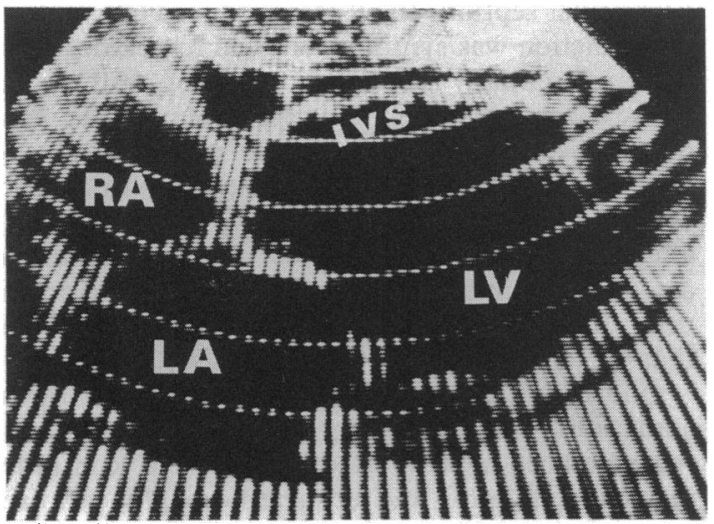

Fig. 2 Cross sectional echocardiogram, subcostal view, showing dilated left ventricle ( $L V$ ) and left atrium $(L A)$ in case 5. RA, right atrium; IVS, interventricular septum.

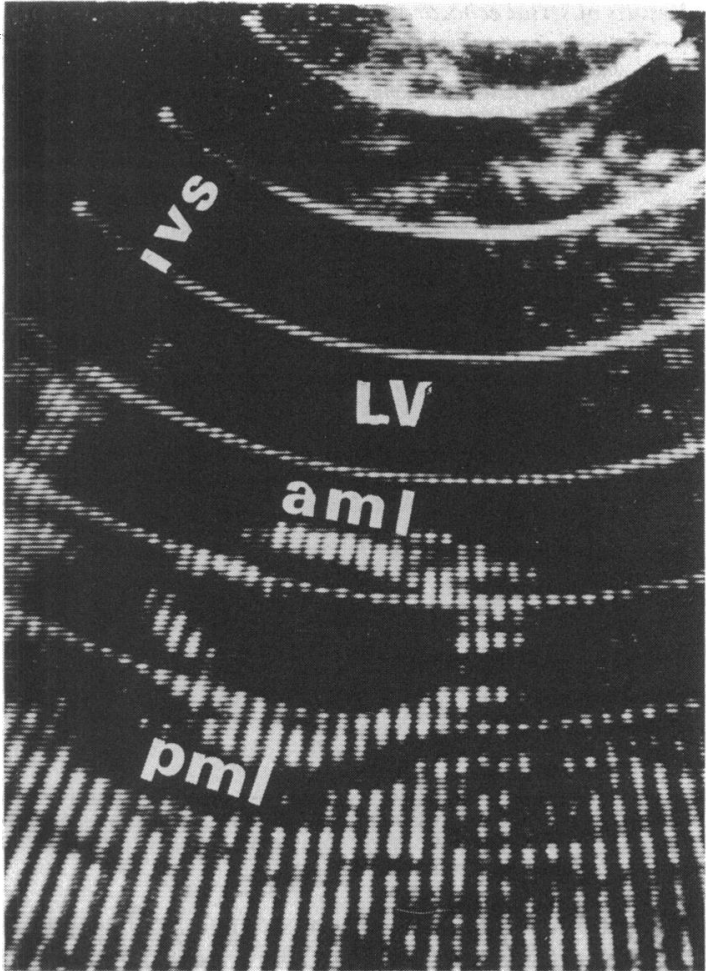

Fig. 3 Cross sectional echocardiogram (case 5), parasternal short axis view, showing dilated left ventricular $(L V)$ cavity and increased anterior mitral leaflet (aml) to interventricular septum (IVS) separation. pml, posterior mitral leaflet.

\section{Discussion}

Heart disease characterised by a dilated left ventricle with impaired systolic function, in the absence of $\dot{\delta}$ systemic hypertension, coronary artery disease, valvar or congenital lesions, and diseases of other systems, is usually classified as dilated cardiomyopathy both in adults and children. Viral myocarditis, however, can produce a similar condition and the disease may cause chronic progressive myo- of cardial damage resulting in a clinical and echo- N cardiographic picture which is essentially indistin- N guishable from dilated cardiomyopathy. ${ }^{6}$ Generally, evidence of viral involvement can only be found early in the disease-often at a time before patients have been evaluated by a physician. ${ }^{7}$ A viral $\stackrel{\leftrightarrow}{?}$ aetiology was proved in four of our patients and $D$ implied in a fifth. In view of histories of antecedent viral like diseases in all of our patients we believe that the myocardial disease was probably related to a viral infection in all of them. In our experience these children often present with progressive respiratory 
distress that requires intensive care. At a later stage, the disease picture is identical to that of dilated cardiomyopathy.

No clear answer has emerged from the debate about the proposed association between endocardial fibroelastosis and dilated cardiomyopathy. Van der Hauwaert et al believe in a strong association and they suggest that in the parasternal short axis view of the left ventricular cavity there are bands of dense echoes along the interior aspect of the left ventricular cavity, most prominently involving the posterior wall, that are highly suggestive of endocardial fibroelastosis. ${ }^{3}$ Using their technique, we found such a picture in only one case (case 1 ). Others ${ }^{2}$ do not accept this association because even histological examination often cannot distinguish between socalled "endocardial fibroelastosis" and "pure" myocarditis. ${ }^{8}$

Goldberg et al found that the posterior wall of the left ventricle is often more severely affected than the septum. ${ }^{2}$ In contrast, in our study we found a symmetrical decrease in the function of the left ventricular free wall and septum. The younger age of our patients may account for these differences. We found no left ventricular thrombi in our patients, whereas Kupferschmid et al found thrombi in three of nine children with dilated cardiomyopathy. ${ }^{5}$ Again our patients were younger than theirs.

In conclusion, we believe that serial echocardiographic examinations are valuable in the evaluation of infants and young children with viral myocarditis or dilated cardiomyopathy and we have not found any need for invasive studies in our cases. We also found that patients in whom clinical, electro- cardiographic, and $x$ ray criteria indicate recovery often have residual left ventricular dilatation and impaired systolic function on echocardiographic studies and hence they require continued follow up.

We thank Mrs Bilha Savell for her assistance. This study was supported by the Nathan Sachs postgraduate award in cardiology and the South African Zionist Federation Medical Committee Fund.

\section{References}

1 Ghafour AS, Gutgesell HP. Echocardiographic evaluation of left ventricular function in children with congestive cardiomyopathy. Am f Cardiol 1979; 44: 1332-8.

2 Goldberg SJ, Valdes-Cruz LM, Sahn DJ, Allen HD. Two-dimensional echocardiographic evaluation of dilated cardiomyopathy in children. Am $\mathcal{F}$ Cardiol 1983; 52: 1244-8.

3 Van der Hauwaert LG, Denef B, Dumoulin M. Longterm echocardiographic assessment of dilated cardiomyopathy in children. Am $\mathcal{f}$ Cardiol 1983; 52: 1066-71.

4 Goldberg S, Allen HD, Sahn DJ. Pediatric and adolescent echocardiography. Chicago: Year Book Medical Publishers, 1975: 38-70.

5 Kupferschmid C, Schmaltz AA, Tacke E, Apitz J, Lang $D$. Left ventricular thrombi in three children with dilated cardiomyopathy: diagnostic procedure and clinical course. Pediatr Cardiol 1984; 5: 65-70.

6 Goodwin JF. The frontiers of cardiomyopathy. $\mathrm{Br}$ Heart If 1982; 48: 1-18.

7 Woodruff JF. Viral myocarditis. Am $\mathcal{F}$ Pathol 1980; 101: 427-79.

8 Hutchins GM, Vle SA. The progression of interstitial myocarditis to idiopathic endocardial fibroelastosis. Am f Pathol 1972; 66: 483-91. 